\title{
THE ASSOCIATIONS BETWEEN SEXUAL VICTIMIZATION AND HEALTH OUTCOMES AMONG LGBQA COLLEGE STUDENTS: EXAMINING THE MODERATING ROLE OF SOCIAL SUPPORT
}

\author{
Eryn DeLaney \\ Virginia Commonwealth University \\ Chelsea Derlan Williams \\ Della V. Mosley \\ Sage E. Hawn
}

Danielle M. Dick, PhD

Follow this and additional works at: https://scholarscompass.vcu.edu/gradposters

Part of the Counseling Psychology Commons

\section{Downloaded from}

DeLaney, Eryn; Williams, Chelsea Derlan; Mosley, Della V.; Hawn, Sage E.; and Dick, PhD, Danielle M., "THE ASSOCIATIONS BETWEEN SEXUAL VICTIMIZATION AND HEALTH OUTCOMES AMONG LGBQA COLLEGE STUDENTS: EXAMINING THE MODERATING ROLE OF SOCIAL SUPPORT" (2020). Graduate Research Posters. Poster 61.

https://scholarscompass.vcu.edu/gradposters/61

This Poster is brought to you for free and open access by the Graduate School at VCU Scholars Compass. It has been accepted for inclusion in Graduate Research Posters by an authorized administrator of VCU Scholars Compass. For more information, please contact libcompass@vcu.edu. 

COLLEGE STUDENTS: EXAMINING THE MODERATING ROLE OF SOCIAL SUPPORT

\section{ABSTRAGT}

The current study tested how sexual victimization was associated with depressive symptoms, post-traumatic stress disorder (PTSD) symptoms, and alcoho Lse college students. Additionally, social support was tested as a moderator. Findings indicated that sexur. symptoms, PTSD symptoms, and AUD symptoms. addition, perceived social support moderated the relation between sexual victimization and depressive symptoms, however, in a direction contrary to hypotheses. In particular, higher sexual victimization Was associaled with greater depressive symptoms support $(b=29, p=00)$, and was not significant among LGBQA students with lower levels of social support $(b=.13, p=26)$. The current study highlights the need to consider the detrimental effects of sexual victimization on health outcomes among LGBQA college students, as well as the mechanisms through relations.

\section{BACKGROUND \& SIGNIFICANGE}

* Sexual minority college students (e.g., people who queer, or asexual: LGBQA) are two to four times more likely to experience sexual victimization compared to their straight-identified counterparts (e.g., Edwards et al., 2015).

* Research have demonstrated that sexual victimization is associated with higher depressive symptoms, PTSD symptom
(e.g., Gilmore et al., 2018).

* Despite the alarming increased risk of sexual assault among LGBQA college students, existing College sampes (eg. Blann Colder, \& Read 2019) and com, Scalco, Radomski, who identify as LGBQA (e. Hequembourg Livingston, \& Parks, 2013), rather than LGBQA college students.

* Understanding how sexual victimization influences mental healh and substance use outcomes, and LGBQA individuals is warranted given societal and institutional adversities targeted at LGBQA individuals that present unique challenges and stressors such as heterosexism and homophobia (Blosnich \& Bossarte,

* The purpose of the current study is to answer the following research questions: (a) are sexual
victimization experiences associated with health outcomes (i.e., depressive symptoms, PTSD symptoms, and AUD symptoms) and (b) are the associations between experiences of sexual victimization and health oulcomes moderated by perceived social support?

Eryn DeLaney, MS, Chelsea Derlan Williams, PhD, Della V. Mosley, PhD, Sage E. Hawn, MS, Danielle M. Dick, PhD

\section{PROGEOURE \& PARTICIPANTS}

* Secondary data was analyzed from Spit 4 Science, an on 2017) at a large US university.

* Students were invited to complete a self-report online survey during their first semester of college and a follow up survey each subsequent spring semester across college and beyond complete, and participants received \$10 compensation.

* This current study included emerging adults who completed follow-up surveys in 2017 d $2^{\text {nd }}$ year post- college.

- Students identified as gay or lesbian (39\%), bisexual $(73 \%)$, queer $(24 \%)$, or asexual $(14 \%)(n=234)$.

* Additionally, about half (56\%) of the participants selfentified as White $(n=132), 16 \%$ as Black or African American Native Alaskan $(n=2), 3.9 \%$ as Hispanic or Latino $(n=9), 0.4 \%$ as Native Hawaiian or Other Pacific Islander $(n=1)$, and $9.8 \%$ listed "more than one race" $(n=23)$.

- Most participants in the current study were female $(74 \%)$ and 8-22 years of age $(M=18.4, S D=.41)$.

\section{MEASURES}

\begin{tabular}{|c|}
\hline $\begin{array}{l}\text { Sexual Victimization: Two items from an abbreviated version of the } \\
\text { Life Events Checklist (LEC). } \\
\text { o Participants were asked to indicate if they experienced (1) sexual } \\
\text { assault or (2) unwanted or uncomfortable sexual experiences in } \\
\text { the past } 12 \text { months. }\end{array}$ \\
\hline $\begin{array}{l}\text { Social Support: Three items adapted from the } 19 \text {-item Social } \\
\text { Support Survey of the Medical Outcomes Study module (Sherbourne \& } \\
\text { Stewart, 1991) } \\
\text { o Items asked about experiences in the past } 12 \text { months and } \\
\text { included: " "low often was someone available to give good advice } \\
\text { about a crisis?" }\end{array}$ \\
\hline $\begin{array}{l}\text { Depressive symptoms: A subset of four items from each construct } \\
\text { from the Symptoms Checklist (SCL-90) } \\
\text { o Items included "Feeling hopeless about the future" in the last } 30 \\
\text { days }\end{array}$ \\
\hline $\begin{array}{l}\text { PTSD symptoms: Four items from the Primary Care PTSD Screen } \\
\text { (PC-PTSD; Prins et al., 2003) } \\
\text { o Items included "Have had nightmares about it or thought about it } \\
\text { when you did not want to?" }\end{array}$ \\
\hline $\begin{array}{l}\text { *AUD symptoms: The } 16 \text {-item measure assessed items related to the } \\
\text { DSM-V AUD criterion. } \\
\text { o Items included "Have you continued to drink even though it was } \\
\text { causing you medical, emotional, or psychological problems?" }\end{array}$ \\
\hline Controls: Sex, age, \\
\hline
\end{tabular}

\section{DISEUSSION}

* Consistent with tenets of the minority stress model (Meyers, 2002), these findings suggest that sexual victimization should be viewed as a facet of minority stress associated with poorer health outcomes among LGBQA college students. These associations, combined with higher reports of heterosexism and discrimination on college campuses among this population, suggests the importance of considering connections among sexual victimization, institutional oppression, sexual identities, and health outcomes.

- Social support did not moderate the relation between sexual victimization and PTSD symptoms and AUD symptoms, which is inconsistent with the literature regarding PTSD symptoms (Hyman, Gold, \& Cott, 2003). To our knowledge, the current study is the first to test the influence of social support on these associations among LGBQA college students. These null findings could be attributed to the measure that combines different types of social support, which may miss some of the specific forms that have been associated with PTSD and AUD symptoms. Thus, future research is needed that independently assesses different types of social support that might moderate the relation between sexual vicimizalion and AUD symptoms.

- However, social support did moderate the relation between sexual victimization and depressive symptoms; however, the direction of effects was contrary to our hypotheses. Specifically, higher sexual victimization was associated with greater depressive symptoms among LGBQA college students with high levels of perceived social support but was not significant among LGBQA college students with low levels of perceived social support.

* It is unclear why social support strengthened the relation between sexual victimization and depressive symptoms. However, prior studies have indicated that social support networks for sexual minority youth, in both peer and family contexts, are limited compared to straightidentified peers (Williams, Connolly, Pepler, \& Craig, 2005). Further, LGBQA youth reported more worries about losing their friendships (i.e., drifting apart or terminating because of conflict) than their straight-identified peers (Diamond \& Lucas, 2004). Additionally, extensive researc has indicated that a majority of sexual victimization is committed by someone (Gross, Winslett, Roberts, \& Gohm, 2006; U.S. Department of Justice, 2003).

* Therefore, it is possible that the perpetrator of sexual victimization may be within LGBQA student survivors' social network and out of fear of losing their friendships, they may avoid disclosing their sexual trauma and withdraw themselves to avoid interacting with their perpetrator or those connected to the perpetrator, which ultimately may increase their depressive symptoms. Additional research is needed in order to
better understand the social networks of LGBTQ student survivors of sexual assault, coping mechanisms with regard to their social netwo and the perpetrator's role in their social network.

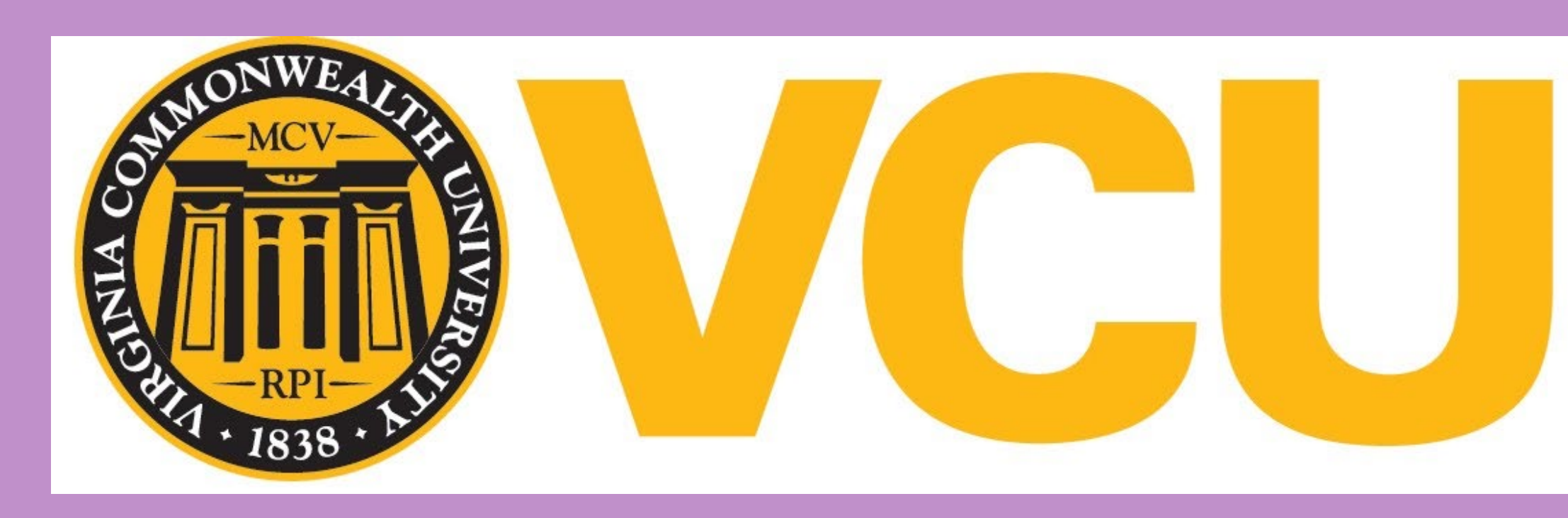

\section{RESULTS}

* The analytic strategy included running a series of regression models in Mplus v7.2 with

* The hypothesized models were tested utilizing social support as the interaction variable.

- Consistent with expectations, sexual victimization was associated with higher levels of PTSD symptoms $(\beta=.45, p<.001)$, depressive
symptoms $((\beta=.21, p<.001)$, and AUD symptoms $(\beta=.34, p<.001)$ * In contrary to expectations, there was no significant moderation effects of perceived social support on the
victimization and PTSD or AUD symptoms

* However, findings indicated that perceived social support moderated the relation between sexual victimization and depressive symptoms $(\beta$ virection contrary to hypotheses

* Simple analysis revealed that higher sexual victimization was associated with greater depressive symptoms among sexual minorities with high levels $(+1 S D)$ of social support $(\beta=.18, p<.001$ ), but the
relation between sexual victimization and depressive symptoms was not significant among sexual minorities with low levels $(-1 S D)$ of social support $(\beta=.03, p=.26$ ) (Figure 1).

- Similarly, perceived social support was related to lower depressive symptoms $(\beta=-.29, p<.001)$, while sex $(\beta=.36, p=.01)$ and race $(\beta=$ mptoms.
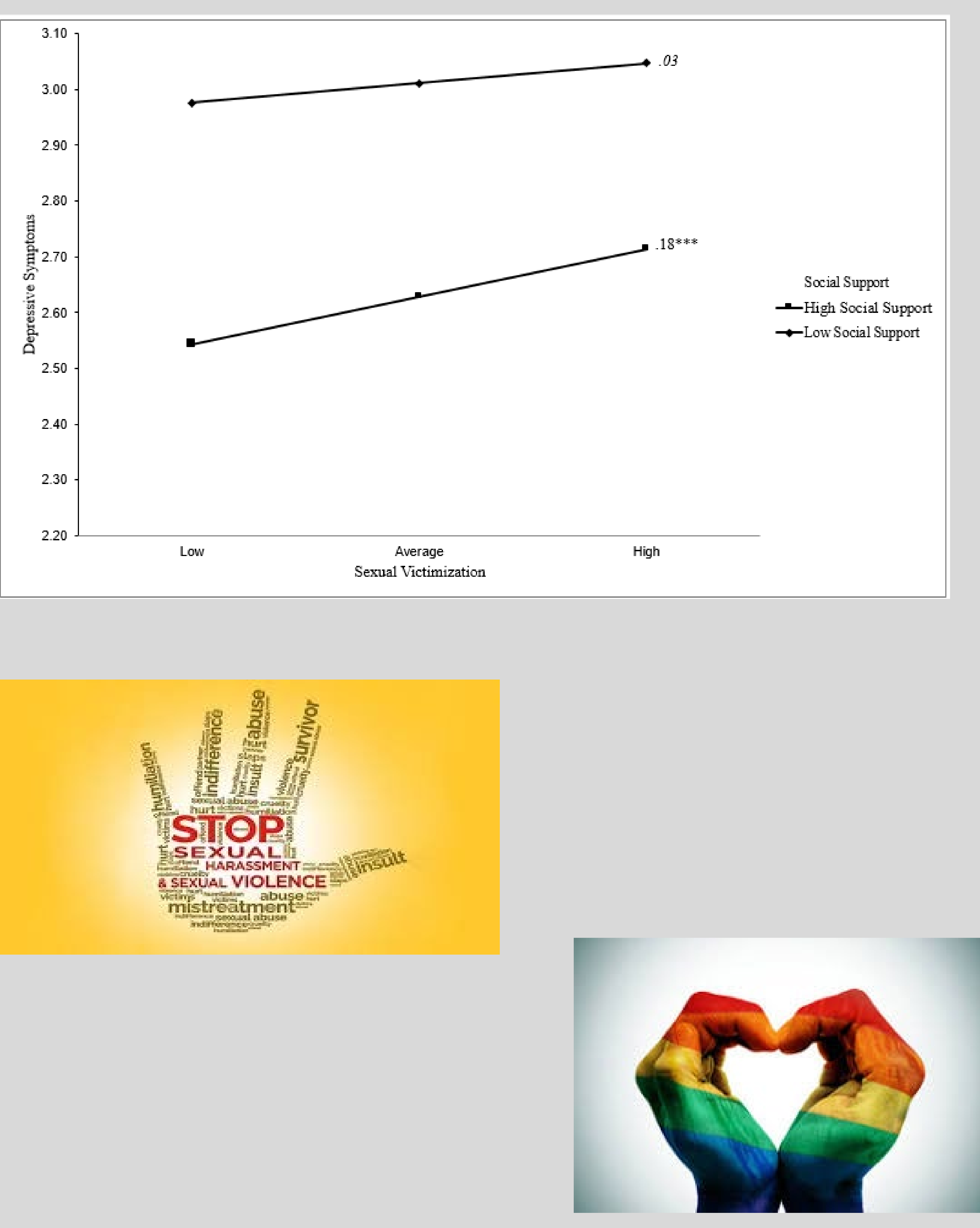